\title{
Factors affecting the use of male-oriented contraceptives: a case study of the Mukarati community, Zimbabwe
}

This article was published in the following Dove Press journal:

Open Access Journal of Contraception

10 September 2012

Number of times this article has been viewed

\author{
Stanzia Moyo' \\ Alfred Zvoushe ${ }^{2}$ \\ Oswell Rusinga ${ }^{3}$ \\ 'Centre for Population Studies, \\ University of Zimbabwe, Harare, \\ Zimbabwe; ${ }^{2}$ Ministry of Education, \\ Sports and Culture, Kadoma District, \\ Zimbabwe; ${ }^{3}$ Department of Physics, \\ Geography and Environmental \\ Science, Great Zimbabwe University, \\ Masvingo, Zimbabwe
}

\begin{abstract}
The subject of male sexuality has long been shrouded by silence and secrecy in Zimbabwe. As such, where contraceptive uptake has featured as part of social studies inquiry, it has tended to do so in the context of a development discourse that focused exclusively on the experiences of women. Marshaling evidence from the survey, key informant interviews, and focus-group discussions (FGDs), this study unearthed factors underlying the uptake of maleoriented contraceptives from men's perspectives. This was done through an exploration of men's knowledge, attitudes, beliefs, and practices pertaining to male-oriented contraceptives and an assessment of the availability, accessibility, acceptability, and affordability of male-oriented contraceptives. The results indicated that despite the fact that men are knowledgeable about maleoriented contraceptives, such knowledge is not being translated into practice. Social construction of masculinity is the primary encumbering block to the uptake of male-oriented contraceptives. In addition, unavailability and unaffordability of vasectomy services in the Mukarati community results in no men opting for the method. The study has thus recommended that the government and other relevant stakeholders may formulate policies that promote information, education, and communication pertaining to male-oriented contraceptives in order to foster the utilization of contraceptives by men.
\end{abstract}

Keywords: contraceptives, masculinity, sexuality, reproductive health

\section{Introduction}

Population issues have been under the spotlight of world conferences since as far back as 1964. However, the first three conferences - Belgrade in 1964, Bucharest in 1974, and Mexico in $1984^{1}$ - heralded the sidelining of the inclusion of male-oriented contraceptives in policy and development. Governments' focus in the aforementioned conferences was on the analysis of fertility reduction from a woman's perspective in order to foster development. In addition, researchers and family planning organizations focused upon female methods of contraception because it was argued that women bear a disproportionate portion of the health and economic consequences of childbearing and rearing. ${ }^{2-5}$ Prior to the International Conference on Population and Development (ICPD) in 1994, the development of male-based contraceptive methods was said to represent a misdirection of resources because contraception was ultimately in the domain of female reproductive health. ${ }^{6,7}$ Thus, the United Nations ${ }^{8}$ defined contraceptive prevalence as "... the percentage of women using contraception among women of reproductive age who are married or in a consensual union." Such a definition clearly depicts the erroneous gender bias where issues to do with contraceptive use were always skewed towards women.
Correspondence: Stanzia Moyo Centre for Population Studies, University of Zimbabwe, Box MP 167 Mt Pleasant, Harare, Zimbabwe Tel +263773806 I3I or +2634333672 Fax +2634333674

Email stanziaImoyo@yahoo.com 
The 1994 ICPD, ${ }^{9}$ the 1995 Platform of Action of the Beijing Fourth World Conference on Women, ${ }^{10}$ the 1996 Harare Declaration, ${ }^{11}$ the 1999 ICPD+5 review conference, ${ }^{12}$ the United States Leadership Against HIV/ AIDS, Tuberculosis, and Malaria Act of $2003,{ }^{13}$ and the 1998 Zimbabwe Population Policy ${ }^{14}$ incorporated men in use of contraceptives. It was a requirement that governments develop appropriate contraceptive methods for couples and individuals. In addition, the methods were supposed to vary. However, it should be argued that all of the aforementioned advocated for the promotion of male involvement in reproductive health in order to protect their female sexual partners and children's health. In fact, none of them took into consideration the fact that men (like women and children) have their own knowledge, attitudes, beliefs, and practices pertaining to male-oriented contraception. Thus issues pertaining to maleoriented contraceptives were not given priority in research, policy, or programming.

In recent decades, male methods of contraception such as coitus interruptus, periodic abstinence, vasectomy, and the condom have been incorporated in fertility-regulation equations. ${ }^{15-24}$ However, it should be noted that the use of male-oriented contraceptives in both developed and developing regions is still relatively low. In developed regions, the $\mathrm{UN}^{5}$ has noted that male methods of contraception account for $27 \%$ compared to $73 \%$ female methods. The same source noted that male condom use, withdrawal, and vasectomy account for $13 \%, 8 \%$, and $6 \%$, respectively. Comparatively, in developing regions, the use of existing male contraceptives accounted for a total of $7 \%$ (withdrawal $1 \%$, male condom $3 \%$, and vasectomy $3 \%$ ) as compared to $93 \%$ for all female methods. ${ }^{5}$ These data clearly show the low levels of use of male-oriented contraceptive methods in both developed and developing countries.

Existing data depict low levels of vasectomy when compared to female sterilization from 2003 to 2011 (Table 1). While $18.9 \%$ of females worldwide were sterilized, only $2.4 \%$ of men were reported to have undergone vasectomy in 2011. In addition, while fewer females in more developed regions reported sterilization when compared with their counterparts in less developed regions, the reverse is true for males (Table 1). There have also been $33 \%, 2 \%$, and $41 \%$ decreases in the uptake of vasectomy in the world, developed, and developing regions, respectively, from 2003 to 2011.

In Africa, the prevalence of vasectomy for all these years has always been $0.0 \%{ }^{1,5,25-30}$ In 2011, vasectomy in Africa was $0.0 \%$, as compared to $2.5 \%, 2.3 \%, 13.7 \%$, and $9.8 \%$ in Europe, Latin America and the Caribbean, North America, and Oceania, respectively. ${ }^{31}$

In Zimbabwe, there is considerable knowledge about male-oriented contraceptives. Zimbabwe Demographic and Health Surveys (ZDHSs) ${ }^{21-23}$ showed these variations in knowledge as follows: vasectomy, $42 \%-49 \%$; condoms, 96\%-98\%; periodic abstinence, 39\%-59\%; and withdrawal, $48 \%-64 \%$. However, it should be argued that the observed levels in knowledge do not translate to practice. ZDHSs ${ }^{21-23}$ reported current practice of male-oriented contraceptives as follows: vasectomy $0.2 \%, 1.0 \%$, and $0.2 \%$; abstinence, $0.4 \%$, $1.0 \%$, and $8.1 \%$; and withdrawal, $1.6 \%, 1.6 \%$, and $13.8 \%$. While all the aforementioned data point to the prevalence of male-oriented contraceptives in developed and developing countries and Zimbabwe in particular, it should be argued that the data only utilize the quantitative approach. As such, data do not leave room to understand content-specific determinants of men's knowledge, attitudes, beliefs, and practices towards male-oriented contraceptives. Therefore, this study goes beyond the customary quantitative boundaries offered in ZDHSs and UN World Contraceptive Use surveys by encompassing the qualitative-methodology approach. The incorporation of qualitative methodology helped to explain the factors underlying the observed prevalence of male-oriented contraceptives in the Mukarati area. Data from qualitative methodology is hoped to influence policy formulation and programming.

It has also been observed that the quantitative analysis of the uptake of male-oriented contraceptives in all UN World Contraceptive Use data sheets and Demographic and Health Surveys is from the perspective of antenatal female attendees. Therefore, it should be argued that this is incongruous because data do not measure directly the prevalence of

Table I Percentage distribution of the prevalence of sterilization

\begin{tabular}{|c|c|c|c|c|c|c|}
\hline \multirow[t]{2}{*}{ Region } & \multicolumn{2}{|l|}{2003} & \multicolumn{2}{|l|}{2005} & \multicolumn{2}{|l|}{2011} \\
\hline & Males & Females & Males & Females & Males & Females \\
\hline World & 3.6 & 20.5 & 3.4 & 20.5 & 2.4 & 18.9 \\
\hline More developed regions & 5.6 & 9.7 & 5.3 & 59.3 & 5.5 & 8.2 \\
\hline Less developed regions & 3.2 & 22.7 & 3.0 & 22.3 & 1.9 & 20.6 \\
\hline
\end{tabular}

UN (2003, 2005, 20II). 
male-oriented contraceptive methods from the perspective of males. By using men as the unit of analysis and entry point for an in-depth exploration of men's knowledge, attitudes, beliefs, and practices (KABP) and the availability, affordability, accessibility, and acceptability of male-oriented contraceptives, this study therefore shifts from the traditional context of investigating male behavior from the perspective of women.

\section{Methods}

\section{Study area}

The research was carried out in Mukarati, which is Ward 4 of Kadoma District. The ward has a total of ten enumeration areas (EAs). All the EAs were purposely selected for the study. In addition, Mukarati is a rural community with people of different backgrounds and religious affiliations. Furthermore, no documented studies of this nature have been done in Kadoma District.

\section{Target population}

Males aged 15-79 years were the target population. This age-range was selected because sexual activity among men starts at adolescence, and unlike women, fathering can go beyond the age of 49 years. In addition, the age limit was set at 79 years in order to avoid memory-loss problems.

\section{Study design}

The study was cross-sectional, triangulating both quantitative and qualitative research methods. FGDs and key-informant interviews were used to collect qualitative data. Quantitative data were collected using the survey method.

\section{Data-collection methods}

\section{Focus-group discussions}

Twelve FGDs (using an FGD guide) were undertaken with sexually active males and females of both younger and older generations. Six FGDs were done with males and the other six with females. Sexually active females were selected so as to validate information obtained from male FGDs. Selection of respondents for each FGD was based on age cohorts and willingness to participate. Each age cohort had its own FGD. Age cohorts of 15-24, 25-34, 35-44, 45-54, 55-64 and $65+$ years were used for the selection of respondents for each FGD. Since FGDs are largely exploratory, it was necessary to get an indication of the prevalence of contraceptive use by males in the community. FGDs also provided data on what the community perceived as the underlying causes of the observed prevalence of contraceptive use by males.
Moreover, FGDs helped to obtain normative information where participants' KABP pertaining to male contraceptive use was drawn upon. Perceptions and evaluative analysis about the availability, accessibility, affordability, and acceptability of reproductive health services to men was also able to be drawn upon in the FGDs.

\section{Survey}

A survey (using a questionnaire) was carried out with 246 males within the age-group 15-79 years. The survey was undertaken in order to quantify the magnitudes of the following: contraceptive uptake by men, KABP of males pertaining to male contraceptives, and the availability, accessibility, affordability, and acceptability of reproductive health services to men.

\section{Sample-size determination}

The sample size was calculated using the formula, $\mathrm{n}=\left(\mathrm{Z}^{2} \mathrm{pq}\right) / \mathrm{e}^{2}$. Where $\mathrm{n}=$ the desired sample size; $\mathrm{Z}^{2}=$ the standard normal deviate (of the $\mathrm{Z}$ scores) usually set at 1.96 , which corresponds with a $95 \%$ confidence interval; $p=$ the proportion of males in the age-group 15-79 years to the total population in Mukarati; $\mathrm{q}=$ the proportion of total population in Mukarati excluding 15- to 79-year-old males ( $1-\mathrm{p})$; and $\mathrm{e}^{2}=$ desired level of precision set at 0.05 .

The total population in the area was 4942 . Total males aged $15-79$ years in the study area was $988 .{ }^{32}$ Therefore, the sample-size calculation was $\left(1.96^{2} \times 0.20 \times 0.80\right) / 0.05^{2}=$ 246 men.

\section{Sampling procedure}

The sampling procedure was done in three stages. Firstly there was the purposeful selection of a ward. In the ward, all the ten enumeration areas were purposely selected. Probability proportionate to size sampling was used to determine the number of respondents from each EA. It should be noted that probability proportional to size sampling was used in three stages: firstly to determine the number of respondents per EA; secondly to determine the number of respondents per age-group in all EAs; and lastly to determine the number of respondents per age-group and per EA (Table 2).

The Central Statistical Office 2002 Master Plan was used to identify the number of households per EA. Simple random selection without replacement was done in order to identify the sampled households. One man per age-group was selected in every household. Where there was more than one man for a particular age-group, simple random selection without replacement was also conducted. 
Table 2 Number of respondents per enumeration area (EA) and per age-group

\begin{tabular}{|c|c|c|c|c|c|c|c|c|c|c|c|}
\hline Age-group (years) & EAI & EA2 & EA3 & EA4 & EA5 & EA6 & EA7 & EA8 & EA9 & EAIO & Total \\
\hline $15-19$ & 12 & 9 & 9 & 8 & 7 & 6 & 7 & 8 & 9 & 10 & 85 \\
\hline $20-24$ & 5 & 2 & 5 & 5 & 3 & 2 & 3 & 3 & 5 & 5 & 38 \\
\hline $25-29$ & 3 & I & 2 & 3 & 2 & 2 & 2 & 2 & 2 & 2 & 21 \\
\hline $30-34$ & 3 & I & I & I & 2 & 2 & 2 & 2 & I & 2 & 17 \\
\hline $35-39$ & I & I & I & I & I & I & I & I & I & I & 10 \\
\hline $40-44$ & 2 & 1 & 2 & I & 2 & 2 & 2 & 2 & 3 & 3 & 20 \\
\hline $45-49$ & I & I & I & I & I & I & I & I & I & I & 10 \\
\hline $50-54$ & I & I & I & I & I & I & I & I & I & I & 10 \\
\hline $55-59$ & I & I & I & I & I & I & I & I & I & I & 10 \\
\hline $60-64$ & 2 & I & I & 2 & I & 2 & I & I & 2 & 2 & 15 \\
\hline $65-69$ & 1 & I & 1 & 1 & I & I & 1 & 1 & I & I & 10 \\
\hline Total & 32 & 20 & 25 & 25 & 22 & 21 & 22 & 23 & 27 & 29 & 246 \\
\hline
\end{tabular}

\section{Key-informant interviews}

Twelve key informant interviews (using a key-informant interview guide) were undertaken. Key informants included health-care providers and religious leaders, both males and females. Six key-informant interviews were randomly selected for each group. Key informants were interviewed because they were well connected and informed community experts. These experts had localized and culturally appropriate firsthand knowledge and insights into the nature of male reproductive health issues in the area. Key informants also provided data on how they deal with male reproductive health problems in the area. In addition, perspectives about men's KABP pertaining to male contraceptives were solicited from key informants. Key informants also provided data on the factors underlying men's utilization of health-care facilities related to contraceptives. They provided confidential incidences, statistics, and conditions that explain implementation problems in their service delivery and recommendations pertaining to contraceptive use among men.

\section{Data management and analysis Quantitative data}

After the data were collected, the questionnaires were given code numbers that were used for tracking errors during data entry. In addition, a dictionary was created for data entry using SPSS software (IBM, Armonk, NY). Double entry and data cleaning was done in order to avoid data-entry errors. A comparison of the data between the two sets of data from the double entry was done in order to check for consistency. Frequency distributions were run from the two parallel data sets. Inconsistent entries were verified with the raw data on the respective questionnaires. SPSS was used to analyze quantitative data. Basic descriptive methods such as frequency distributions and cross-tabulations were run in order to highlight the relationship between dependent and independent variables.

\section{Qualitative data}

Qualitative data were transcribed and typed. Ethnograph (Qualis Research, Colorado Springs, CO) was the software package used for analyzing qualitative data. In the analysis of data, themes pertaining to determinants of the uptake of male contraceptives were identified. These data were then used to explain and expand findings from the quantitative data.

\section{Ethical considerations}

The study respected freedom in participation. Participants voluntarily consented to participate without coercion. There was no deception when informed consent was sought. The study adhered to research principles pertaining to privacy and confidentiality.

\section{Results}

\section{Sociodemographic characteristics of respondents}

The sample was generally youthful. The majority of the respondents (52\%) were youths (Table 3). The 25-29-year age-groups had $9 \%$ of the respondents, compared to $8 \%$ from the 40-44-year age group. The age-groups 45-49 years and 50 years and above constituted $5 \%$ and $16 \%$ of the respondents, respectively. The majority of the respondents (29\%) reported that they were Protestants, while 23\% reported that they were Catholics. Pentecostals comprised about $18 \%$ of the sample. The other religious affiliations constituted $17 \%$ of the sample, while $13 \%$ did not belong to any religious denomination.

Consistent with the youthfulness of the population, $48 \%$ reported that they had never married, while $43 \%$ reported being married/cohabiting (Table 3 ). Approximately $6 \%$ and $3 \%$ reported to be divorced/separated and widowed, respectively. Generally, the sample was highly educated, 
Table 3 Percentage distribution of respondents' demographic and socioeconomic characteristics

\begin{tabular}{|c|c|}
\hline Characteristics & Percentage \\
\hline \multicolumn{2}{|l|}{ Age-group (years) } \\
\hline $15-19$ & 36.2 \\
\hline $20-24$ & 15.9 \\
\hline $25-29$ & 8.5 \\
\hline $30-34$ & 6.9 \\
\hline $35-39$ & 4.1 \\
\hline $40-44$ & 7.7 \\
\hline $45-49$ & 4.5 \\
\hline $50-54$ & 3.3 \\
\hline $55-59$ & 3.3 \\
\hline $60-64$ & 5.7 \\
\hline $65-69$ & 4.1 \\
\hline Total & 100 \\
\hline \multicolumn{2}{|l|}{ Marital status } \\
\hline Never married & 48.4 \\
\hline Married & 42.7 \\
\hline Divorced/separated & 6.1 \\
\hline Widowed & 2.8 \\
\hline Total & 100 \\
\hline \multicolumn{2}{|l|}{ Religion } \\
\hline Catholic & 23.2 \\
\hline Pentecostal & 17.9 \\
\hline Protestant & 29.3 \\
\hline None & 13.0 \\
\hline Other & 16.7 \\
\hline Total & 100 \\
\hline \multicolumn{2}{|l|}{ Occupation } \\
\hline White-collar worker & 19.2 \\
\hline Blue-collar worker & 45.4 \\
\hline Student & 22.9 \\
\hline None & 12.5 \\
\hline Total & 100 \\
\hline
\end{tabular}

Note: $\mathrm{n}=246$.

since only $5 \%$ of the respondents reported that they have never been to school. The majority $(60 \%)$ reported having attained an ordinary level. Those who had attained an advanced level constituted an estimated $9 \%$, while those with tertiary or more education constituted about $11 \%$ of the respondents. About $15 \%$ of respondents reported having ended at primary level. A huge percentage, $45 \%$, were bluecollar workers, while an estimated $19 \%$ were white-collar workers. A small proportion, $13 \%$, were not employed, while $23 \%$ were students.

\section{Knowledge about male contraceptives}

Knowledge about male contraceptives was universal in this study. About $96 \%$ of the respondents acknowledged having heard of male-oriented contraceptives. Knowledge of the presence of modern male contraceptives on the market was also universal (98\%). However, when traditional and modern male contraceptive methods were grouped, the most widely known modern method was the male condom ( $98 \%$ ) as compared to vasectomy (68\%) (Table 4). All FGDs supported the widespread knowledge about male condoms. One man in an FGD asserted that:

Knowledge about condoms is almost universal across all age-groups. You can even ask a 5-year-old kid, and he will tell you everything you would want to know about male condoms.

When asked about the traditional male methods of contraception, more respondents (87\%) were aware of withdrawal than the rhythm (55\%). It was interesting to note the issue of male contraception was not a modern phenomenon. FGDs with males and females aged 65+ years revealed that they depended on withdrawal and rhythm methods for birth spacing when the wife was still in the reproductive age-group.

Information dissemination on contraceptives was significantly high, with respondents relying on various sources of information, shown in Table 5. The majority of respondents (87\%) reported the radio as the main source of contraceptive information. This was followed by friends $(60 \%)$, while the newspaper and television were reported by about $55 \%$ and $53 \%$, respectively.

While sources of information about contraceptives in general are available in Mukarati, it was interesting to note that the majority of respondents $(89 \%)$ did not know of any source of information focused only on male contraceptives. When asked about the possible best male contraceptive information dissemination sources, the majority of respondents $(65 \%)$ cited the radio. Brochures, television, and educational seminars were cited by $11 \%, 16 \%$, and $4 \%$ of respondents, respectively.

Respondents were asked about their most preferred contraceptive. Most of the respondents (84\%) preferred the male condom (Figure 1). Withdrawal and rhythm were reported by $11 \%$ and $4 \%$ respondents, respectively. Vasectomy was reported to be a very unpopular contraceptive

Table 4 Percentage distribution of respondents' knowledge of male-oriented contraceptives

\begin{tabular}{ll}
\hline Method & Percentage \\
\hline Modern methods & \\
Vasectomy & 68.0 \\
Male condom & 98.1 \\
Traditional methods & \\
Withdrawal & 87.0 \\
Rhythm & 55.2 \\
\hline
\end{tabular}

Note: $\mathrm{n}=256$ (multiple response). 
Table 5 Percentage distribution of respondents' perceptions on sources of male contraceptive information

\begin{tabular}{ll}
\hline Source of information & Percentage \\
\hline Radio & 87.1 \\
Television & 53.2 \\
Newspaper/magazine & 54.5 \\
Posters & 26.0 \\
Teachers & 35.1 \\
Health workers & 38.1 \\
Friends & 59.5 \\
Workmates & 25.0 \\
Other & 8.0 \\
\hline
\end{tabular}

Note: $\mathrm{n}=236$ (multiple response).

method, as only $1 \%$ of the respondents preferred the method. Men who participated in FGDs echoed the sentiment that virtually no known male contraceptives were preferable. However, the majority were bitter about vasectomy and very against it. They argued that vasectomy is contrary to the cultural definition of masculinity. A 45-year-old man in one FGD remarked that:

Vasectomy is tantamount to castration. If a man is castrated, he then ceases to be a man and to maintain his position as a father. You will not be able to differentiate a man from a woman should the man agree to be sterilized.

Another man in an FGD of the 65+ age-group fumed:

The true gospel is that vasectomy is and should never be tolerated by men. Men have a privilege right from birth to be fertile until death. So why should we be sterilized? We are not oxen which are castrated so that they can be easily controlled.

The difficulty of reversibility of vasectomy was another factor that was found to be hindering the uptake of this method as a favorable contraceptive method. One male in an FGD of men aged 20-29 years asserted that:

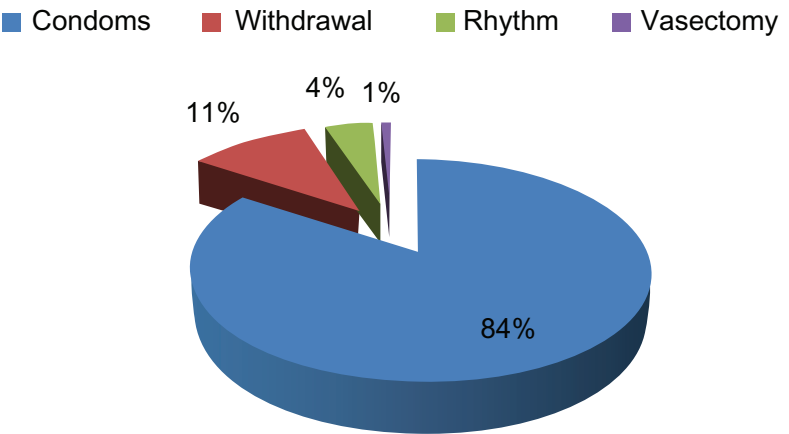

Figure I Percentage distribution of respondents' most preferred contraceptive method.

Note: $\mathrm{n}=246$.
I was going to prefer vasectomy as an option for male contraception. However, the fact that it is an irreversible surgical operation makes me shiver and hate this process for good. In addition, men understand that anything can go wrong (death and permanent disability) during the procedure.

Most men did not consider male sterilization to be a feasible option. During the FGDs, when the moderator would try to begin a dialogue on male sterilization, men would often steer the discussion toward female sterilization.

Why talk about male sterilization when women are ready to get sterilized? Women do not do labor-intensive work and mostly stay at home. Thus they can more easily recover from sterilization than men. More so, childbearing and rearing is a domain for women.

Inadequacy of information about vasectomy has made the method very unpopular among men in Mukarati. One male FGD participant in age-group 40-49 years asserted:

We do not have firsthand information about vasectomy. We only rely on vasectomy information from our friends in cities whom we think are better informed than us. However, most of the time, I have also realized that the friends are also ill informed. The dissemination of information is just like a Chinese-whisper game. Should the first participant fail to appreciate and correctly comprehend the information, that's a receipt for disaster to the receivers at the end of the rope.

Results suggest that due to inadequate information about vasectomy, misconceptions exist about the method. Such misconceptions make men uncomfortable in using vasectomy as an option for contraception. All men in FGDs were bitter about the so-called negative effects of vasectomy. Such effects encroached onto the definition of machismo. One man in an FGD (supported by the rest of the participants) posited:

Our learned friends from the cities always tell us about the negative effects of vasectomy. It is alleged the method has the following impacts: men become weak; men cannot do any heavy work; limbs become weak and painful; and men get colds and fever. So I should think you agree with me that the aforementioned conditions really destroy my manhood. Come heaven, come hell, I will never opt for vasectomy.

Low vasectomy-preference levels reported by men in FGDs and the survey were also substantiated by 
key informants. One health nurse from Mukarati clinic reported that not even a single man had visited their clinic enquiring about the method. On the other hand, religious leaders also stated that they do not approve vasectomy as a method of contraception. More so, they do not even encourage men to use this method since it is contrary to God's perception about a consummate man. One of the religious leaders in a key-informant interview argued:

God has commanded procreation to mankind in Genesis

I verse 28 (“... be fruitful and multiply") and Leviticus

26 verse 9 ("I will bless you and give you many children").

So if one is to be sterilized, then, he is going parallel to

God's expectations of an ideal man.

Another religious leader in a key-informant interview asserted:

Discussions about male condom use in the church promote promiscuity. Thus their use and distributions should not be promoted within the church boundary.

Results seem to suggest that male condoms are the most available method of contraception rather than vasectomy. The majority of respondents (99\%) stated that male condoms were available, compared to those stating availability of vasectomy $(1 \%)$. In all FGDs, respondents highlighted that male condoms were available in retail outlets, clinics, and community-based distributors. On the other hand, keyinformant interviews with all health-care providers confirmed the unavailability of vasectomy in the Mukarati area. One of the health-care providers echoed:

Vasectomy is a surgical operation performed by a qualified medical doctor. Clinics are the only medical facilities in this area. Thus none of them have the capacity and mandate to perform surgical operations.

Condoms seem to be accessible by the majority of men in Mukarati. A huge proportion, $80 \%$, of the respondents reported that they were comfortable in accessing condoms from clinics, stores, and community-based distributors.

Respondents were asked on whether they were comfortable in accessing male condoms. All the respondents in the age-group 40-44 years assented (Table 6). This was followed by $99 \%$ of respondents from the age-group 50-54 years. It is important to note that adolescents had the lowest proportion of respondents, $50 \%$, who felt comfortable in accessing male contraceptives.

In adolescent FGDs, respondents also argued that they could not easily access condoms from clinics, stores, or
Table 6 Percentage distribution of respondents who were comfortable in accessing contraceptives by age

\begin{tabular}{ll}
\hline Age-group (years) & Percentage \\
\hline $15-19$ & 50.2 \\
$20-24$ & 79.5 \\
$25-29$ & 76.2 \\
$30-34$ & 89.4 \\
$35-39$ & 93.0 \\
$40-44$ & 100.0 \\
$45-49$ & 97.2 \\
$50-54$ & 99.3 \\
$55-59$ & 97.5 \\
$60-64$ & 92.9 \\
$65-69$ & 90.1 \\
\hline
\end{tabular}

Note: $\mathrm{n}=246$ (multiple response).

community-based distributors (CBDs). This was largely attributed to cultural perceptions and lack of privacy and confidentiality. One adolescent boy posited:

Condoms might be available, but I realized that our community stigmatizes sexually active adolescents. Culturally, most people don't expect us to be sexually active since we are not married. Hence, they also don't believe that we have sexual problems.

Another boy bitterly asserted that adolescents are not comfortable in accessing condoms because of lack of privacy and confidentiality. He posited:

Issues of privacy and confidentiality are not adhered to at condom collection points. In clinics, condoms are placed at the outpatient, consultation, and treatment rooms, which in most cases will be full to capacity.

Another adolescent boy stated:

If you want condoms from shops and CBDs, they would ask who will have sent you to buy or collect condoms. One of the shopkeepers promised me that she was going to tell my parents that I bought some condoms.

Analysis by marital status (Table 7) revealed that all widowed respondents were comfortable in accessing contraceptives, while $93 \%$ of the divorced respondents

Table 7 Percentage distribution of respondents who were comfortable in accessing male contraceptives by marital status

\begin{tabular}{ll}
\hline Marital status & Percentage \\
\hline Never married & 85.7 \\
Currently married & 70.4 \\
Divorced/separated & 93.3 \\
Widowed & 100 \\
\hline
\end{tabular}

Note: $\mathrm{n}=246$ (multiple response). 
reported that they were comfortable. About $70 \%$ of married respondents reported that they were comfortable when accessing contraceptives. Sociocultural expectations of men tend to be their major inhibiting factors in accessing contraceptives.

Condoms seem to be affordable in the Mukarati area. The majority of respondents $(98 \%)$ reported that condoms were free, especially the Panther brand. The aforementioned view was substantiated by one health-care provider in a keyinformant interview as she asserted:

The Ministry of Health and various stakeholders are really serious when it comes to the distribution of condoms. At the moment, free male condoms are scattered everywhere and we hope they are being effectively used.

Results seem to suggest that other brands of condoms are also affordable. The majority of respondents (99\%) in the survey, FGDs, and key-informant interviews stipulated that at most US\$1 is paid for other brands like Protector Plus, Carex, and Moods.

Most respondents, $72 \%$, reported that they were able to discuss condom use with sexual partner(s). In all FGDs, it was reported that condom use requires mutual understanding between partners. However, it was also noted that most unmarried men at times never bother to get consent to or not to use condoms from their partners. They make decisions on their own. Married men reported that discussing condom use with partners is only applicable in extramarital relationships.

Results revealed that vasectomy as a male contraceptive option is not prevalent in Mukarati. All the respondents revealed that they had not gone for male sterilization. Withdrawal and rhythm methods were prevalent in the Mukarati area, but to a limited extent. Only a paltry $5 \%$ and $3 \%$ of sexually active men ever used and were currently using withdrawal or rhythm methods, respectively. Analysis by religious affiliation revealed that the aforementioned methods are commonly used by Marange Apostolic church affiliates. This was also supported by key-informant interviews with religious leaders from Marange Apostolic church. The leader asserted:

We always rely on the rhythm and withdrawal methods.

Vasectomy and condoms have a medical component which is contrary to our operating principles as a church.

The majority of respondents, $95 \%$ and, $97 \%$, have never used nor are currently using withdrawal and rhythm, respectively.
All FGD findings confirmed survey results. One of the respondents discarded the rhythm method by positing:

Rhythm is more biological and needs constant monitoring of the woman's reproductive cycle. This whole process is difficult to track. It needs someone with a sober mind.

On withdrawal, one male respondent postulated:

The timing of withdrawal is very tricky because that is the climax point and the whole purpose of sexual intercourse.

Generally, use of the male condom was widespread in Mukarati. The majority of respondents (97\%) reported having used male condoms. However, current use of male condoms is moderate. Only $60 \%$ of respondents assented. Analysis by marital status showed that the majority (89\%) of unmarried men (single, divorced, widowed) were the ones who were currently using condoms. There was also an insignificant variation of male condom use by level of education.

Results in this study revealed that the men in marital unions never opt to use condoms as either a protective method or as a family planning method. An insignificant proportion, $2 \%$, had attempted to use condoms in marital unions. It was interesting to note that there were no variations by levels of education, religion, or occupation. Condom use in marital unions was criticized in all male FGDs. Note this remark from a man in the FGD 30-39 years:

Really, what will be the essence of getting married in the first place if one decides to use a condom with his wife? Furthermore, if one uses condoms with his wife, there will be no differences between a married wife and a girlfriend. Condoms are for girlfriends and extra partners.

One man also asserted:

I don't entertain the use of male condoms in my marriage. When I married my wife, beast for the bride prize had no condoms when her fathered accepted them.

Machismo as defined by culture was cited in male FGDs as another deterrent to male contraceptive use. One man asserted:

The patriarchal system in our Shona culture empowers men with the obligation to decide when to use male condoms both as a family planning method and protection against infections. A woman in our culture is supposed to be submissive. 
Men also argued that they do not use male condoms in marital unions because of their wives' attitudes towards condoms. One male asserted:

I was in for a high jump when I initiated male condom use to my wife. She argued that she was not a prostitute. Her belief up to now is that male condoms were meant for prostitutes and unfaithful wives.

Female FGDs, especially of the older age, showed that their negative perceptions are major stumbling blocks to condom use by men. One woman in the 50-59-year FGD fumed:

I am not a prostitute, right. In addition, how can I use condoms with my only dearest husband? Even if I am advised to use male condoms by health-care providers as a means of avoiding HIV and STI reinfections, I will never adhere to that. I will never accept such dirty tricks. I will rather fail to have sex totally than to use a male condom.

One married woman in the 25-29-year age group reiterated that married women at times prefer to see their husbands using condoms mainly as a family planning method. However, sociocultural factors prohibit them from making sexual decisions. She said:

If you suspect that your husband will be playing games, condoms must be used for protection. But we (women) do not have the capacity to negotiate condom use. On the other hand, men do not even want to hear anything about condom use in marriages.

Multiple partnering seems to be common in Mukarati. The majority of respondents $(60 \%)$ reported that they had a regular partner (other than spouse). A significant proportion of respondents who had a regular partner, $43 \%$, reported that they used a condom with a regular partner. Condom use with regular partners was also analyzed by marital status. Forty-six percent and $52 \%$ of the married respondents and unmarried respondents, respectively, reported they used a condom during their last meeting with regular partner (Table 8). It is important to note that $3 \%$ and $5 \%$ of widowed and divorced respondents, respectively, reported condom use in their last sexual encounters with regular partners.

Respondents were asked about their frequency of male condom use with a regular partner. It was interesting to note that the majority, $83 \%$, of respondents were not consistent when it comes to condom use with a regular partner. A substantial proportion, 53\%, reported that they sometimes used condoms, while $33 \%$ stated they used condoms most
Table 8 Percentage distribution of respondents who used a condom with regular partner by marital status

\begin{tabular}{ll}
\hline Marital status & Percentage \\
\hline Never married & 51.9 \\
Married/cohabiting & 40.6 \\
Divorced & 4.7 \\
Widowed & 2.8 \\
Total & 100 \\
\hline
\end{tabular}

Note: $\mathrm{n}=65$.

of the time (Figure 2) with a regular partner. Only a paltry $14 \%$ always used the male condom.

Respondents were asked if they would discontinue condom use in sexual relationships (especially regular partners). Most of the respondents (76\%) reported that men have got a tendency of discontinuing condom use at some point in sexual relationships. Variations in responses were analyzed by age (Table 9). All respondents in the age-group 35-39 years reported that men have got a tendency of discontinuing condom use, while about $80 \%$ respondents in the age-group 15-19 years supported the notion. Ninety percent of respondents in the age group 65-69 years also reported that men tend to discontinue condom use in sexual relationships.

In FGDs with both men and women, it was reported that men tend to quickly develop trust (resulting in discontinuation of condom use) in sexual relationships for unknown reasons. However, one man in a 20-29-year FGD reported that males develop some form of trust of their girlfriends resulting in discontinuation of male condom use. He echoed:

When a girlfriend shows signs of seriousness and become a full-time partner, men will quickly discontinue condom use. We have got a tendency of rushing in trusting these girlfriends. I believe this behavior is inborn.

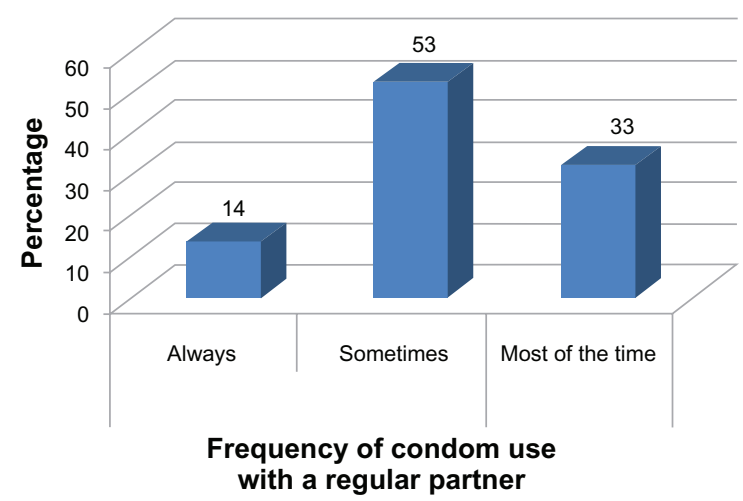

Figure 2 Percentage distribution of respondents by frequency of condom use with regular partner.

Note: $\mathrm{n}=65$. 
Table 9 Percentage distributions of respondents' perceptions on discontinuing condom use in relationships by age-group

\begin{tabular}{ll}
\hline Age-group (years) & Percentage \\
\hline $15-19$ & 71.9 \\
$20-24$ & 74.4 \\
$25-29$ & 95.2 \\
$30-34$ & 76.5 \\
$35-39$ & 100 \\
$40-44$ & 73.7 \\
$45-49$ & 63.6 \\
$50-54$ & 87.5 \\
$55-59$ & 75 \\
$60-64$ & 64.3 \\
$65-69$ & 90 \\
\hline
\end{tabular}

Note: $n=246$.

It was also interesting to note that men tend to have a negative perception about male condoms. The majority of respondents $(86 \%)$ believed that condoms have some pores that allow pathogens to pass through. On the other hand, the majority of respondents (76\%) also argued that male condoms defeat both the thrill and objectives of sexual intercourse. All FGDs assented with the aforementioned survey results. However, key-informant interviews contradicted the aforementioned perceptions. One male health-care provider argued:

The issue of pores on condoms is just a myth. If condoms are used correctly and consistently, they always yield better results.

Another male health-care provider asserted:

Sexual pleasure is never affected by condom use. Sexual pleasure lies in the brain.

\section{Discussion}

The results revealed that knowledge about male-oriented contraceptive methods is nearly universal. The majority (96\%) of the men in the sample had heard of male-oriented contraceptives. Analysis by method of contraception revealed that $98 \%, 87 \%$, $68 \%$, and $55 \%$ of males had heard of the male condom, rhythm, vasectomy, and periodic abstinence, respectively. These findings are congruent with those from earlier, nationwide surveys in Zimbabwe, as shown in ZDHSs. ${ }^{21-23}$ Information dissemination about contraceptives was also high, with the majority of respondents (87\%) reporting radio as the main source of contraceptive information. Newspapers and television were reported by $55 \%$ and $53 \%$, respectively.

It was surprising to note that despite widespread knowledge about male-oriented contraceptives, there was no positive relationship between knowledge and practice. Condoms were locally available, as reported by $99 \%$ of males. In addition, they were also affordable, as reported by $98 \%$ of males. Evidence from FGDs and key-informant interviews revealed that the Panther brand was freely available, while the Carex, Moods, and Protector Plus brands were said to cost at most 5 rand.

While there was widespread knowledge about the male condom, and that condoms were available and affordable, it was surprising to note that only $60 \%$ of men indicated current use of male condoms. It was interesting to note that married men $(2 \%)$ were less likely to use male condoms compared to unmarried men $(89 \%)$. Previous studies have also noted relatively lower prevalence of contraceptive use among married men compared to unmarried men. ${ }^{21-23,33-35}$ While male condoms offer dual protection, the issue of acceptability and accessibility of male condoms hindered their use. In this study, males argued that they did not use condoms in marital unions because of married women's perceptions about male condoms. Both males and females argued that married women associate condoms with infidelity and lack of trust. Even in extramarital affairs, results of this study revealed that men have a tendency of discontinuing the use of male condoms because of the "false trust" of their regular partners, a situation which exposes men to HIV and sexually transmitted infections. ${ }^{36-38}$ Besides reducing the thrill and objective of sexual intercourse, as also noted by Chiroro, ${ }^{37}$ condom use in marital unions in this study was said to be contrary to the concept of "lobola" (bride price) and male sexual virility. Men argued that they would not use condoms in marital unions because the beasts for bride prize had no condoms in their feet.

While men aged $20+$ years said they could easily access condoms, it was noted that the situation was different for male adolescents. They argued that society expects them to refrain from practicing sexual intercourse before marriage. Resultantly, they argued that they would not access male condoms due to fear of community stigmatization of promiscuity. In addition, adolescent males argued that male condoms are placed on the outpatient desk and treatment and consultation rooms at the clinic. It has been asserted that the aforementioned places will be full to capacity thereby, contradicting principles of privacy and confidentiality, a top priority in adolescent reproductive health-seeking behavior. Similar findings were echoed by Moyo, ${ }^{35}$ Mujuru, ${ }^{36}$ and Dhliwayo. ${ }^{38}$

Results in this study show that vasectomy was the least preferred ( $1 \%)$ and never used by men in the Mukarati community, 
though $68 \%$ of men had heard of the method. This was largely because misconceptions about the method affected its acceptability. The method was associated with and equated to castration. Similar findings were also observed in studies by Khalifa ${ }^{39}$ and Muhondwa and Ruternberg. ${ }^{40}$ The irreversibility of the method, contradiction to an ideal man (a birthright of fertility until death), and its negative impact on masculinity were also reasons against the use of the method. Men quickly diverted sterilization to women. They argued that they would opt for the wife to be sterilized primarily because of social norms that assign the burden of family planning to women. In addition, men argued that women do not do labor-intensive work and mostly stay at home. Pursuant to the aforementioned, it was perceived that women can more easily recover from sterilization than men.

Men had negative perceptions about vasectomy because they were ill informed about the method. They relied on vasectomy information from their friends in cities whom they also agreed could be ill informed and have negative attitudes about male sterilization. It was alleged that vasectomy leads to weakness, which contradicts the definition of masculinity. Some men were also worried that something might go wrong during the procedure, resulting in death or permanent disability. Men feel that the sterilization operation is easier to perform on women than on men. However, vasectomy is in fact a safer and less invasive procedure than tubal sterilization..$^{35,41}$

Absence of vasectomy services in the community's family planning program affected the accessibility of the method for men in the Mukarati community. It was noted that the method was a surgical operation only performed at major referral hospitals by qualified medical professionals. The operation was said to be beyond the reach of men in the rural Mukarati area. Pursuant to the aforementioned, it was noted that the absence of vasectomy services in Mukarati partly explained the genesis of the misconception and negative attitudes of men towards vasectomy. Thus it is assumed that if vasectomy services were promoted and available in the area, it would be popular and widely used by men.

Knowledge about the traditional methods of male contraception showed that the methods were not a new phenomenon. The majority of respondents, $87 \%$ and $55 \%$, were aware of withdrawal and periodic abstinence, respectively. Similar findings were even higher than findings from ZDHS studies. ${ }^{21-23}$ Surprisingly, only a paltry 5\% and $3 \%$ of respondents reported current use of withdrawal and rhythm, respectively. Religious reasons were the major explanations for acceptability of these methods. The results from this study revealed that only men in the Marange Apostolic Church were the ones who practiced the aforementioned male-oriented contraceptives. Their argument was that male condoms and vasectomy have a biological component, which is contrary to their principles and guidelines of not utilizing health services. On the other hand, men argued that the timing of periodic abstinence is very difficult and requires a sober mind. This finding is commensurate with findings from ZDHS, ${ }^{23}$ which asserted that only a meager $6 \%$ of men were able to identify the fertile period of a woman. Withdrawal was said to be difficult since the timing (climax of sexual intercourse) of its administration is difficult to manage. More so, both methods were said to defeat the thrill and objectives of marriage and sexual intercourse.

\section{Conclusion}

The study noted that knowledge about male oriented contraceptive methods was nearly universal among male respondents. However, the use of these contraceptives is influenced by a wide array of factors. Cultural constructions of masculinity that ascribe prominence to fertility and male adventurousness in sexual activities influenced the context where the use of a male-oriented contraceptive method was seen as appropriate. A false sense of trust also mired the use of male condoms in extramarital affairs. Availability, accessibility, affordability, and absence of correct information about male contraceptives negatively impacted on the uptake of vasectomy. Thus the study recommends there must be widespread information, education, and communication about male-oriented contraceptives. This must be the responsibility of the government (through the relevant ministries) and the church.

\section{Disclosure}

The authors report no conflicts of interest in this work.

\section{References}

1. United Nations. World Contraceptive Use 2003. New York: UN Department of Economic and Social Affairs, Population Division; 2004.

2. Freedman R. The contribution of social science research to population policy and family planning program effectiveness. Stud Fam Plann. 1987; 18:57-82.

3. Hammouda A. Contraceptive use, fertility differentials and family planning issues in Jordan. Paper presented at the symposium on the Jordan Husbands' Fertility Survey; June 4, 1987; Amman, Jordan.

4. Meredith P. Male Involvement in Planned Parenthood, Global Review Strategies for Programme Development. London: International Planned Parenthood Federation; 1989.

5. United Nations. World Contraceptive Use 2010. New York: UN Department of Economic and Social Affairs, Population Division; 2011.

6. Cummings D, Bremner W. Prospects for new hormonal male contraceptives. Endocrinol Metab Clin North Am. 1994;23:893-922. 
7. Ezeh AC, Seroussi M, Raggers H. Men's fertility, contraceptive use and reproductive preferences. Demographic and Health Surveys Comparative Studies. 1996;18:1-40.

8. United Nations. World Contraceptive Use 2004. New York: UN Department of Economic and Social Affairs, Population Division; 2005.

9. UNFPA. The State of World Population 2005. New York: UN Population Fund; 2005.

10. United Nations. World Contraceptive Use 2001. New York: UN Department of Economic and Social Affairs, Population Division; 2002.

11. Danforth N, Roberts P. Better Together: A Report on the African Regional Conference on Men's Participation in Reproductive Health. Baltimore: Johns Hopkins Center for Communication Programs; 1997.

12. Boonstra H. Meeting the sexual and reproductive health needs of people living with HIV. Guttmacher Policy Rev. 2004;9.

13. Zimbabwe National Economic Planning Commission. National Population Policy 1998. Harare. National Economic Planning Commission, Government of Zimbabwe.

14. Keith L, Keith D, Bussell R, Wells J. Attitudes of men toward contraception. Paper presented at the first annual conference of the World Population Society; 1974; Washington, DC.

15. Davidson A, Ahn KC, Chandra S, Guerrero RD, Dubey DC, Mehryar A. The Acceptability of Male Fertility Regulating Methods: A Multinational Field Survey. Geneva: World Health Organization; 1985.

16. McGinn T, Bamba A, Blama M. Male knowledge, use and attitudes regarding family planning in Burkino Faso. Int Fam Plann Perspect. 1989;15:84-87.

17. Posner J, Mbodji F. Men's attitudes about family planning in Dakar. J Biosoc Sci. 1989;21:279-291.

18. Central Statistics Office [Zimbabwe] and Macro International Inc. Zimbabwe Demographic and Health Survey 1984. Calverton, Maryland: Central Statistics Office [Zimbabwe] and Macro International; 1985.

19. Central Statistics Office [Zimbabwe] and Macro International Inc. Zimbabwe Demographic and Health Survey 1988. Calverton, Maryland: Central Statistics Office [Zimbabwe] and Macro International; 1989.

20. Central Statistics Office [Zimbabwe] and Macro International Inc. Zimbabwe Demographic and Health Survey 1994. Calverton, Maryland: Central Statistics Office [Zimbabwe] and Macro International; 1995.

21. Central Statistics Office [Zimbabwe] and Macro International Inc Zimbabwe Demographic and Health Survey 1999. Calverton, Maryland: Central Statistics Office [Zimbabwe] and Macro International; 2000.

22. Central Statistics Office [Zimbabwe] and Macro International Inc. Zimbabwe Demographic and Health Survey 2005-06. Calverton, Maryland: Central Statistics Office [Zimbabwe] and Macro International; 2006.

23. Central Statistics Office [Zimbabwe] and Macro International Inc. Zimbabwe Demographic and Health Survey 2011. Calverton, Maryland: Central Statistics Office [Zimbabwe] and Macro International; 2012.
24. United Nations. World Contraceptive Use 2005. New York: UN Department of Economic and Social Affairs, Population Division; 2006.

25. United Nations. World Contraceptive Use 2006. New York: UN Department of Economic and Social Affairs, Population Division; 2007.

26. United Nations. World Contraceptive Use 2007. New York: UN Department of Economic and Social Affairs, Population Division; 2008.

27. United Nations. World Contraceptive Use 2008. New York: UN Department of Economic and Social Affairs, Population Division; 2009.

28. United Nations. World Contraceptive Use 2009. New York: UN Department of Economic and Social Affairs, Population Division; 2010 .

29. United Nations. World Contraceptive Use 2011. New York: UN Department of Economic and Social Affairs, Population Division; 2012.

30. Central Statistics Office. Provincial Census Report: Mashonaland West. Harare: Government Printers; 2002.

31. Institute for Resource Development. Zimbabwe Demographic and Health Survey Summary Report 1994. Harare. Central Statistical Office; 1994.

32. Rwabukwali CB, Schumann DA, McGrath JW. Culture, sexual behaviour. Sep. 1994;6:3-16.

33. Ityai M, Paul D, Aloys U. Heads, Tails or Equality? Men, Women and Reproductive Health in Zambia. Nairobi: Centre for African Family Studies; 2000

34. Mhloyi M. Women's Participation in Development: The Role of Family Planning. Harare: Friedrich Erbert Stiftung; 2008.

35. Moyo S. Adolescent Reproductive Health Issues: A Case Study of Mhondoro-Ngezi. Unpublished paper. Harare: Centre for Population Studies, University of Zimbabwe; 2008.

36. Mujuru P. Adolescent Reproductive Health Problems: A Case Study of a Mbare High-Density Surburb. Unpublished paper. Harare: Centre for Population Studies, University of Zimbabwe; 2008.

37. Chiroro P, Mashu A, Muhwava W. The Zimbabwean Male Psyche: with Respect to Reproductive Health, HIV, AIDS and Gender Issues. Harare: Centre for Applied Psychology; 2002.

38. Dhliwayo E. Reproductive Health Issues of Adolescents at Mount Pleasant High School. Unpublished paper. Harare: Population Studies, University of Zimbabwe; 2009.

39. Khalifa MA. Attitudes of urban Sudanese men toward family planning. Stud Fam Plann. 1988;19:236-243.

40. Muhondwa E, Rutenberg N. A Study of the Effects of the Vasectomy Promotion Project on Knowledge, Attitudes, and Behaviour among Men in Dar es Salaam. Dar es Salaam: Population Council; 1997.

41. International Conference on Population and Development Programme of Action; 1994. UNFPA New York
Open Access Journal of Contraception

\section{Publish your work in this journal}

Open Access Journal of Contraception is an international, peerreviewed, open access, online journal, publishing original research, reports, reviews and commentaries on all areas of contraception. In addition to clinical research, demographics and health-related aspects, the journal welcomes new findings in animal and preclinical studies

\section{Dovepress}

relating to understanding the biological mechanisms and practical development of new contraceptive agents. The manuscript management system is completely online and includes a very quick and fair peer-review system. Visit http://www.dovepress.com/testimonials.php to read real quotes from published authors. 